\title{
"Abortion? That's for Women!" N arratives and Experiences of Commercial Motorbike Riders in South-Western Uganda
}

\author{
Stella N yanzi $i^{1}$, Barbara N yanzi² and Kalina Bessie ${ }^{2}$
}

\begin{abstract}
Although constitutionally illegal, induced abortion is a vital reproductive health option in U ganda. This paper analyses men's narratives about meanings of, and experiences with, abortion. M en play significant roles in abortion as instigators, facilitators, collaborators, transporters, advisors, informers, supporters or punishment givers. $M$ any participants were knowledgeable about abortion. A ttitudes were ambivalent, with initial reactions of denial and relegation of abortion to women's private domains. Further exploration, however, revealed active support and involvement of men. Interpretations of abortion ranged from 'dependable saviour' to 'deceptive sin'. Though a private action, abortion is socially scripted and often collectively determined by wider social networks of kinsmen, the community, peers, law and religion. A disjuncture exists between dominant public health discourse and the reality of local men who interact with women and girls as wives, lovers, sex sellers, mothers, daughters and sisters. Interventions targeting men about abortion should include safe sex education, provide safe abortion services and create stronger social support mechanisms. Policy and law should incorporate local knowledge and practice. (A fr J R eprod H ealth 2005; 9[1]: 142-161)
\end{abstract}

\begin{abstract}
RÉSUMÉ
"L 'avortement? Cela c'est pour les femmes!" N arrations et témoignages des auto-cyclistes commerciaux au sud-ouest de l'O uganda. Q uoique l'avortement provoqué so it constitutionnellement illégal, il demeure une option importante de la santé de reproduction en 0 uganda. Cet article fait une analyse des narrations de la part des hommes sur la signification del'avortement et leurs expériences faceà l'avortement. Les hommes jouent des rôles importants en tant qu'instigateurs, animateurs, collaborateurs, transports, conseillers, informateurs, soutiens ou donateurs de punition. Beaucoup de participants étaient renseignés sur l'avortement. Les attitudes étaient ambivalentes et il y avaient des réactions initiales des dénégations et du renvoi de l'avortement au domains privés de la femme alors qu'une exploration davantage, a révélé un soutien et une implication actifs. Les interprétations de l'avortement variaient d'un sauveur sur qui l'on peut compter "jusqu'à un péché déceptif". Q uioqu'une action privée, l'avortement est préparé d'avance et souvent collectivement déterminé par un réseau social plus large de parents de la communauté, des pairs, la loi et la religion. II y a une disparité entre le discours de la santé publique dominante et la réalité des hommes locaux qui entretiennent des rapports entre les femmes et les jeunes filles en tant qu'épouses, amantes, vendeuses de sexe, mères, filles et soeurs. L'intervention qui vise les hommes à l'égard del'avortement doit comprendrel'éducation sexuelle sans danger, assurer les services del'avortement sans danger et créer des mécanismes de soutien social plus forts. La politique générale et la loi doivent incorporer la connaissance et la politique locales.(R ev A fr SantéR eprod 2005; 9[1]: 142-161)
\end{abstract}

KEY WORDS: A bortion, attitude, perception, support

${ }^{1} \mathrm{~L}$ ondon School of H ygiene and Tropical M edicine, Keppel Stree, L ondon W C 1E 7H T. ${ }^{2}$ M edical R esearch C ouncil Programme on A ID S in U ganda/ U ganda V irus R esearch Institute, U ganda.

Correspondence: Stella N yanzi, H PU, PH P, L S H T M , Keppe Stret, L ondon W C 1E 7H T. E -mail: snyanzi@ yahoo.com 


\section{Introduction}

Induced abortion is constitutionally illegal in U ganda unless if it is biomedically critical to the health of the mother or fetus. $\mathrm{N}$ ational reproductive health surveys $s^{1,2}$ report that unsafe induced abortions are still widespread and among the leading causes of maternal mortality. The local vox pop (particularly the booming $\mathrm{FM}$ radio stations, private newspapers, magazines and the non-government-owned television channels) present a picture of widespread use and knowledge of the practice. This is woven into common gossip, conversations, rumours and pop music in south-western U ganda. H owever, there is scanty research-based literature about abortion in this context, perhaps due to the illegality of the practice.

This paper analyses the narrative and dialogue of members of an all-male employment group of commercial motorbike riders, locally called bodabodamen, about their experiences with abortion, its meanings, and lay constructions in their context. Specifically focusing on men's perceptions, deconstructions and lay interpretations of abortion elucidated their role in this largely socially constructed practice.

\section{W hy Study Bodabodamen?}

In sub-Saharan A frica, reproductive health studies generally tend to focus on recruiting female participants as key informants. M en's perspectives, experiences and reproductive health are often not researched in their own right, but rather as offshoots of what women encounter. A ccording to Ratcliffe et al, men are most often considered as part of the context in which women's fertility is achieved. M en commonly enter the picture as risk factors for the transmission of infection or as barriers to women's reproductive goals. M en's economic contribution is often represented by socio-economic indicators in models of women's fertility. ${ }^{3-5}$ F urthermore, male figures not only play a pivotal role in the politics, economics and decision-making of women's reproductive health, they also experience it as co-actors. Thus, the recently growing urgency for including men in reproductive health initiatives is timely. ${ }^{6}$ Programme experiences and dynamics of the HIV / AID S epidemic highlight the rationale for greater male involvement, albeit initial feminist fears regarding diversion of limited resources from women-centred approaches to include men's concerns. ${ }^{7}$

As an occupation group that is exclusively male, bodabodamen is an ideal category to study men's reproductive health. This indigenous employment group evolved out of a high demand for efficient inconspicuous transport for ferrying smuggled items (and passengers) across the $\mathrm{K}$ enya- $U$ ganda border during regimes of economic collapse. O ver time, the bodaboda phenomenon has grown to spread throughout rural and urban U ganda. ${ }^{8}$ Prior to our study, no research had been conducted among bodabodamen.

B odabodamen is a social category that is locally portrayed as 'adult men who spoil young schoolgirls', stereotypically presented suggesting and/ or having sex with minors, in anti-HIV/ AIDS health education campaigns. Their daily incomes, material assets, including their motorbike and high mobility levels, make them particularly attractive to young students in search of quick gain in exchange for sexual services. ${ }^{9}$ 0 ur study investigated sexual behaviour among bodabodamen. ${ }^{10}$

A bortion featured heavily in the discussions about sex, sexuality, health and reproduction. During field work, the three authors, who are not trained in biomedicine, were variously approached by study participants in search of 'safe abortion' services such as knowledge, referral, backing or the service itself. This triggered further investigation into the topic. This paper analyses those narratives surrounding abortion. 
$D$ istrict $H$ ealth P rofile

Masaka $\mathrm{D}$ istrict is one of the oldest in $\mathrm{U}$ ganda, with a total land area of $4560.4 \mathrm{~km}^{2}$. It has a total population of 876,474 , majority (89\%) of whom are based in rural areas. The male:female ratio is $50.35: 49.65$. The predominant ethnic group is the Baganda, and the main religion is Roman Catholicism. A griculture is the main source of livelihood for $74.3 \%$ of the population, employment income contributes $8.52 \%$ of district income and $7.91 \%$ comes from trading.11,12

According to the Directorate of District $H$ ealth Services, there are 35 public health facilities including one hospital, 27 registered nongovernmental health facilities made up of two mission hospitals, 83 drug stores registered for profit, and five ambulances for the district. ${ }^{12}$ The $D$ irectorate of $D$ istrict $H$ ealth Services centrally monitors and coordinates the health manpower. An assessment of maternal health services in $M$ asaka D istrict ${ }^{13}$ indicated that although health services in the district are of acceptable quality and sufficient demand exists for them, access to health facilities is limited. O nly about $49 \%$ of the district population lives within five kilometres to a facility. 0 nly $30 \%$ of childbirths are attended by trained health providers..$^{13}$ There are various levels of care that deliver safe motherhood interventions.

The overall literacy rate in the district is $47 \%$; $65 \%$ male and $59.2 \%$ female. School enrolment levels increased with the introduction of universal primary education (UPE). Two hundred and twenty thousand children were enrolled under the scheme, while 43,357 were enrolled as nonUPE pupils. Femalestudents have a higher dropout rate from schools (personal communication with the district education office). There are 454 primary schools, 47 secondary schools, 13 tertiary institutions, three vocational institutes and two nursing schools in the district.

\section{M ethods}

We triangulated both the qualitative and quantitative research techniques. After a pilot study in which instruments were pre-tested and accordingly adjusted, we recruited 221 bodabodamen to respond to a semi-structured questionnaire administered by each of the authors. Participants were often recruited at their stages, where they parked while waiting for passengers. Thereafter, 14 focus discussion groups were conducted with a select group of participants who were willing and able to talk in a group setting. ${ }^{14,15}$ This was followed by two rounds of 40 in-depth interviews, in which emerging themes were further perused on an individual level. We particularly focused on individual experiences and attitudes during the interview sessions. Ten case studies of individuals who had gone through particularly relevant experiences were further followed up by the first author. At the end of this session, we conducted two participatory workshops in which questions and problems raised by participants during preceding sessions were discussed in an interactive manner. These workshops also provided qualitative data.

A ll qualitative data were gathered in the local language (Luganda) and recorded on audio tapes. These were transcribed verbatim, translated into English and entered into computer. Field notes and debriefing minutes were recorded after each field session, and then entered into computer. The texts were coded using A tlas.ti (Scientific Software D evelopment, Berlin) - a computer programme based on the grounded theory, and designed to assist in the analysis of large volumes of qualitative data. ${ }^{16}$ $\mathrm{N}$ umerical analysis of data from the questionnaire utilised standard computer-based techniques using E pi Info 6 (E pidemiology Programme 0 ffice, CD C, Atlanta).

A frican Journal of Reproductive $H$ ealth V ol. $9 \mathrm{~N} 0.1$ A pril 2005 
"A bortion? That's for women!" N arratives and E xperiences of Commercial M otorbike R iders in South-W estern U ganda. . .

\section{$\mathrm{E}$ thical $\mathrm{C}$ onsiderations}

Scientific clearance and ethical approval were provided by the science and ethics committee of the Medical Research Council Programme on AIDS in U ganda/ U ganda Virus Research Institute. Permission to recruit participants was obtained from the different stage managers. Individual verbal consent was sought from each participant at each phase of data collection. A few participants refused to consent because of time constraints. Confidentiality was maintained by assigning identification tags to participants instead of their names, information was stored in password protected databases, and only the research team had access to participants' raw data in the form of tapes and scripts. In order to ascertain anonymity of participants, all identifiers including names of people and stages were changed.

\section{Results}

D emographic $D$ escription

Participants' mean age was 23 (range 17-40) years. Majority (76\%) belonged to the Baganda tribe. Catholic was the major religious denomination $(56 \%)$, followed by the Muslim (31\%) and Protestant (10\%). E ducation levels were mostly low, with the largest proportion (69\%) stopping at primary school level, $28 \%$ attaining some $0^{\prime}$ level education and only three participants had post-0' level training. Most (79\%) of the men had bodaboda job as their only source of income, while $21 \%$ had other jobs including digging, animal husbandry, tailoring, bricklaying and petty trading. Reported incomes were not fixed but depended largely on market forces of demand and supply, ranging from 1,000 to $15,000 \mathrm{U}$ ganda shillings on a 'bad business day' and 5,000 to 30,000 on a 'good day' (exchange rates: US\$1 = UShs1,800/ =). B odabodamen earn their pay at the end of each trip; they have a constant inflow of cash.

A frican Journal of Reproductive $\mathrm{H}$ ealth $\mathrm{V}$ ol. $9 \mathrm{~N} 0.1 \mathrm{~A}$ pril 2005
The Paradox es of A bortion

Consistent with literature, all participants in the individual interviews acknowledged the fact that abortion is a common practice used by 'people in stress' (abeebizibu, literally meaning those with problems). E ven those bodabodamen who strongly condemned the practice admitted its popularity. Seventeen individual interviewees provided detailed narratives about abortion in their personal sexual partnerships. Three of these participants discussed their abortion stories outside the framework of the research schedule; they booked appointment with the researchers after completion of the first round of interviews.

All the bodabodamen knew that abortion is illegal in the country. Several of them said imprisonment is inevitable if it comes to the knowledge of certain groups of individuals in the society. These include policemen who could not be bribed to drop charges, religious leaders, local administrative (local council) officials, disgruntled greedy parents (often the pregnant girl's), a moralistic neighbour, traditionalist kin ties, formal school authorities and jealous peers. They reported that the boy who is responsible for the pregnancy would be liable for imprisonment or payment of fines to the girl's family. They lamented the common lack of punishment for the doctors or other paramedical personnel who carry out the procedure, or the girl's relatives who often put pressure on the couple to seek abortion, or even the girl whose physical body is the medium of crime.

D iscussions about health personnel who conduct abortion often included the scandalous stories about a prominent long established physician in the region who lost his practicing license because of several cases of unsafe abortion he was reported to have conducted. The bodabodamen felt that this doctor had been unfairly victimised by the system of justice, since many other physicians and health personnel who were renowned for the same crime continued to offer the service unabated. 


\section{A frican Journal of R eproductive $H$ ealth}

There was high level knowledge of induced abortion among the respondents. They knew how it happens, where abortion could be procured, names and addresses of various service providers, the price range, various forms of abortion, and possible consequences. However, their accounts were interwoven with misconceptions and incredulous stories, an evidence of their lack of knowledge of women's bodies. Participants clearly distinguished between induced abortion (ok uggyamu olubutto) and spontaneous abortion (otherwise called miscarriage) (olubutto ok uvaamu). The vernacular expressions clearly leave no room for confusing one form of the practice with the other, because while the former points to an active action meaning 'to remove a pregnancy', the latter is passive, meaning 'a pregnancy gets out'. In L uganda language it was clear which version of abortion participants were discussing, unlike in other anthropological studies ${ }^{17}$ that reported lack of local distinctions between the two.

These bodabodamen tended to lump all providers under one all-embracing L uganda term, basawo (loosely meaning health personnel), unlike in a Cameroonian study ${ }^{18}$ where participants identified four distinct sources of abortion services. This could be linked to the traditional $\mathrm{K}$ iganda medical system, which does not promote specialisation but rather has one provider treating a range of illnesses. Further investigation revealed that 'private' or 'self-employed' practitioners who often owned a clinic are perceived to be the most common providers of abortion services. This includes other health personnel who do not have registered premises but have operational venues like their homes or a colleague's clinic room where they schedule appointments for abortion. The boundaries of this category are fluid because several doctors or health personnel employed in government hospitals simultaneously operate or are employed in private clinics. Therefore, while public records report that induced abortion is not conducted in public hospitals, bodabodamen reported the opposite. Some claimed that abortions are conducted in government and missionary hospitals as well as in smaller health facilities.

Participants mentioned names of wards in the hospitals that were reputed for facilitating abortions. 0 thers reported that only consultations and appointments are made with particular doctors and midwives in the hospital space, and arrangements made to meet at another private venue where the abortion is conducted. A few others said that it is totally impossible to procure abortion within the formal hospital environment(s). The men variously mentioned names, addresses and even contact information of personnel who facilitate abortions. Some names were repeatedly mentioned in all the different study locations, revealing that specific practitioners who offer the service may be widely known. O thers were mentioned only in specific localities. The health personnel were described as 'young ambitious doctors who are just beginning to work' or 'long established physicians, midwives and paramedics'. Some local pharmacists and drug shop staff were also mentioned to prescribe and/ or sell medications to facilitate abortion in the home of an aborting mother.

Traditional medical practitioners were also frequently mentioned as providers of abortion services. Three herbalists were particularly reputed for successfully conducting abortions. A few participants dismissed traditional healers, claiming that they are fake, unprotected and often having fatal outcomes. Bodabodamen reported that traditional herbal preparations for inducing abortion are also provided by elderly relatives who are not necessarily socially recognised healers. TheK iganda peoplebelieve that knowledge about herbs, medicines and spiritual cures is revealed by the ancestors to lay people who pass it on to their descendants. This perception is held and preserved by the elderly, especially women grandmothers, mothers and paternal aunts - who still adhere to traditional cultural beliefs and practices. These provide advice, instructions and 
"A bortion? That's for women!" N arratives and E x periences of Commercial M otorbike R iders in South-W estern U ganda. . .

actual services regarding abortion. Though they were discussed under the pretext of social pressures leading to abortion, deeper analysis revealed that when the aborting girl (and sometimes her sexual partner) succumb to pressure, these relatives provide support networks and the girl (or the couple) does not undergo the experience alone. A bortion is transferred from a private to a shared experience. F riends and peers were reported to be another invaluable source of advice and knowledge about abortion.

Bodabodamen were important informants about sources of abortion services because motorbike taxi is regarded as the favourite mode of transportation for clandestine abortion seekers. It is relatively more private, cheaper and convenient; takes passengers to their exact destinations and can wait for them, unlike other public transport options. ${ }^{10}$ Bodabodamen spoke proudly of facilitating transportation to renowned abortion service providers in the district.

$K$ nowledge of substances taken for abortion was limited to generic categories including herbal mixtures, tablets, syrup and injections. $G$ enerally, participants were not conversant with specific names of substances and products taken to induce abortion. A herb, locally called oluwok 0 , was the only named product. The following are excerpts from the in-depth interviews:

Ssali: They might take herbal concoctions or swallow tablets.

Interviewer: What tablets?

Ssali: I do not know. All that I know is that they take tablets.

Interviewer: How was it done?

Peter: She told me she was injected. Interviewer: Where was it done? Peter: In a clinic in Masaka town. She was given an injection and tablets and the abortion was done.

The language and terms of the biomedical model of health are far removed from that of the lay participants. Consequently, men used broad A frican Journal of Reproductive $\mathrm{H}$ ealth $\mathrm{V}$ ol. $9 \mathrm{~N} 0.1 \mathrm{~A}$ pril 2005 generic terms to refer to the treatment options their partners received. It is hard to know the actual pharmacological content of therapy because further probing about specific names of medications yielded expressions like 'doublecoloured capsules', 'big wide white tablets', 'a normal injection ... nothing special about it' and 'thick white liquid in a bottle'. This characterises respondents' knowledge of medications that facilitate abortion within the local context to be 'secret' or even 'sacred', protects biomedical service providers from suspicious investigators, and renders them essential gatekeepers into a tightly locked network of abortion professionals in situations like U ganda where the practice is illegal.

A pparently, there was some confusion about contraceptives commonly referred to as famille or FP (family planning). While some participants were aware that these methods are employed to prevent conception, others thought that the pills offered to women facilitate abortion. In fact a few of the participants were strongly convinced that pregnant women in need of abortion services are offered contraceptive pills by both drug shop owners and other biomedical personnel.

Interviewer: H ow is the abortion carried out? Do you know how one has an abortion?

Kamya: I hear that women are injected with injections, which have medicines that make the thing come out. I think the medicine they use to carry out abortions is called family planning medicine. A woman is injected with this medicine and she has the abortion.

In the focus group discussions participants mocked the seemingly ironical name that biomedical professionals use to refer to abortion - small operation. This is perhaps a lay interpretation of the biomedical concept of minor surgery usually applied to induced abortion. The men expressed horror (sometimes amidst 
laughter) at how biomedical professionals regard a big and potentially dangerous health condition as a 'small operation', a reflection of contrasting perspectives between health providers and the consumers.

The ambiguity and ignorance about medications is also evident to a less extent in discussions on the traditional medicine therapeutic model. The conversation below reveals the lack of in-depth knowledge about herbs and traditional remedies used for abortion by traditional healers:

Interviewer: How do the rest who do not go to hospitals or clinics carry out the abortions?

Charles: They take traditional medicines. Interviewer: What exactly?

C harles: I do not really know, but I hear that they make concoctions from herbs. And that they take it just like they take mululuuza (a local herb used to cure malaria) and the abortion is done.

Interviewer: What is the herbal concoction called?

Charles: I do not know its name.

Interviewer: Where do they get it from? C harles: Somewhere near [deleted village], lives a woman who makes the concoctions for distribution.

Participants were particularly knowledgeable about the lay model of abortion therapy. They frequently mentioned that drinking heavy concentrated brews of black tea, paraffin, which is readily available as fuel for cooking or lighting house lamps, set off abortion in the privacy of the aborting woman's home.

Prices for abortion were not uniform. They ranged from as little as 3,500 U ganda shillings for traditional herbs to $60,000 \mathrm{U}$ ganda shillings for terminating a six-month old pregnancy. Participants claimed that the fees for an abortion could be negotiated depending on the venue of the abortion, skill and reputation of the practitioner, gestational age and the likelihood of complications. They also claimed that abortion service providers tend to use external displays of wealth to determine the price. For example:

Fred: It is wise not to go with your motorbike but to go walking because if he sees the vehicle he will think that you have more money and charge you higher.

$\mathrm{H}$ enry: Me, I think it is better to leave the girl to go alone because if you are together the doctor will know that it is the man paying. Then he will double his price.

T tendo: Yes. E ven the way the girl looks. If she is dressed expensively and she is speaking E nglish, hewill know that she is rich and the money will be more. Kityo: $O r$ if it is her parents who are talking, the price will be very expensive.

\section{M arriage: TheE xcusefor $A$ bortion}

$\mathrm{N}$ arratives about respondents' marital status revealed the multiplicity of meanings, lay interpretations and local applications of the concept 'marriage' to these bodabodamen. M arriage, which is a composite category of standard quantitative surveys, defied all and any attempts of standardisation or coding. After intense discussion about, and reflection upon questionnaire data, in addition to feedback from the participants, 110/ 221 men said that they were married. In the focus group discussions and indepth interviews, many of the bodabodamen said that they are 'single' while in town and 'married' while in the village. Many of them are seasonal rural-urban migrants ${ }^{8}$ who maintain a 'wife' in their sending village and live as transient bachelors in the town suburbs or engage in both serial and concurrent multiple partnerships, or acquire varying levels of other permanent sexual partners. Such permanent sexual partners include frequently utilised commercial sex workers, regular non- 
resident sexual partner, short-term cohabitant or a second wife. As discussed elsewhere ${ }^{10}$, 'marriage' has several nuances in this socio-cultural context.

A nalysis of data from the focus group discussions revealed difficulties of and contradictions within the socially accepted norm of monogamy in this predominantly Catholic society. Bodabodamen discussed the limitations of the 'holy sacrament of monogamous marriage'. This was provided as one of the initial excuses for seeking abortion, especially if the pregnant woman is a sexual partner other than the socially known 'wife'. Some of the in-depth interview respondents stated: "I told her that I was already married and her pregnancy was going to bring problems for me." Such problems include the possibility of losing the marital spouse if she learns about the pregnancy, the desire to settle down with one wife in these modern times, the cost of adding another pregnant partner to already existent dependants, social stigma and exclusion resulting from being labelled an adulterer or a promiscuous or unfaithful husband. H ence, the excuse of monogamy is often associated with other factors.

In addition, participants reported that married men are socially expected to be controlled, responsible and socially mature especially if they already have their own children. This means that they are not expected to openly indulge in extramarital sexual relationships, and if they do the general societal expectation is that they would exercise great caution, meet clandestinely and conceal any evidence of the extramarital unions such as 'an outside pregnancy.' Participants discussed ploys used by men, including denial, when confronted by their spouse about extramarital relationships. They deceitfully refer to other sexual partners as a cousin or another distant relative, tactfully liaising with an informed close male friend to falsely claim ownership of the new sexual partner. Therefore, an unexpected pregnancy, which tends to publicise the otherwise private, unrecognised and often denied sexual union between a married man and an extramarital sex partner is mostly discussed in the light of unnecessary attention which has to be terminated as fast and efficiently as possible. The urgency of the abortion is regarded as more critical if the pregnant female is a young schoolgirl.

Simon: I did not have money to marry her because my first wife had just delivered a baby. So the only solution was to tell her to take the thing out. I was not prepared for the quarrelling from my wife. Eh, eh! She asked me for money to give the doctor. I gave it to her very fast.

Tim: Eh, people will blame you if you are a married man and you spoil someone else's child.

Kityo: They may even wish the same thing happens to your own daughters.

Such discussions about the reciprocal nature of fate were common. Participants said the irresponsible behaviour of impregnating young women, specifically schoolgirls, is not consistent with the societal expectations and character of married men. Bodabodamen variously stated: "... ok wo kweyebuula ate nga oli mufumbo", meaning debasing oneself and yet a married man! Shame and social stigma are higher for married men if the pregnant female is not their socially recognised spouse. Thus, the need for abortion in this case arose out of social pressure and the need to avoid 'the accusing finger' of society. Societal demands were reported to outweigh individual choice and preference, which may mean giving birth to the child.

Participants said that pregnancy and childbirth come with added demands on the male partner to support and maintain the pregnant female (sometimes along with her other dependants). There is the financial and material obligations that come with each new child. Participants claimed that it is too costly to maintain 
a pregnant woman and to later raise a child. Therefore, abortion is an efficient solution to the problems of cost and affordability for these men. It often means that there would be no interruptions in the life of the man; his life would continue unperturbed if the abortion goes well.

There was limited discussion about married men suggesting abortion to their marital spouses. This was mentioned in the focus group discussions as a practice that happens sometimes. $\mathrm{N}$ one of the participants reported having resorted to abortion within marital relationships.

A few participants argued about the possibility of marrying the new pregnant woman instead of having the abortion. These largely fell into three categories. The Muslim men argued that abortion is sinful, but polygamy is accommodated within the Islamic framework. Thus, they would rather marry the new pregnant woman than have an abortion. This was exemplified by the narrative of one case study; a 21-year-old Muslim man who married his extramarital partner when she conceived his child. He now has two wives in two separate homesteads.

The second category comprised men who claimed that they would break up with their first wife and marry the newly pregnant partner. Reasons for this decision revolved around comparing the outward appearance of the two women, their usefulness in terms of hard work or productivity, and the social value that they add to the man's public image.

$M$ en in the third category claimed that they would be 'forced' into marrying the pregnant woman instead of having an abortion. Such force includes outward threats of imprisonment, large fines or excommuni-cation from the clan if the man does not marry the pregnant woman, fear of the girl ending her life, peer pressure from friends who either laugh at the 'less than modern village-based spouse' or tease the man for his single state, or even pressure him to wed the girl out of fear of punishment. This pressure was reported to affect both married and unmarried men. The third category was mostly discussed in the focus group discussions.

Participants claimed that abortion is just one out of many options available to single men in case their relationship resulted in an unplanned pregnancy. In such a case, a man could either marry the girl willingly if her family consents, accept responsibility for the pregnancy but not support the mother, support the mother without necessarily marrying her, deny all responsibility for the child but stay within the vicinity, shun all responsibility and run away to a new area where he cannot be traced, ignore the pregnancy, end up in prison for a short while and then be bailed out, pay a fine to the girl's family and go on with his life, or be forced into marriage with the girl but later break up. A bortion becomes necessary for single men if the girl is in school. Some participants also reported that sometimes single men claim to be too young to be fathers, or too poor to afford the cost of fatherhood and, thus, facilitate abortion of their fetus.

\section{Schoolgirls and A bortion}

The discussions of these bodabodamen revolved around a new law in U ganda that provides for the imprisonment of adult men who are reported to have sexual relationship with a schoolgirl, particularly if she conceives. At the time of fieldwork, the local press carried several reports of adults who were reported, arrested, tried and either fined or sentenced for impregnating students. Though the law was promulgated by 'feminist politicians', participants reported that the relatively less wealthy men (who cannot afford the large sums of money for bribing law enforcement agents such as policemen, magistrates and local administrators) are mainly affected. A midst laughter, the men cited several stories about themselves and their friends who had served prison terms ranging from six months to three years because of this crime.

The gravity of the offence is usually judged by how much 'damage' is perceived to have been 
"A bortion? That's for women!" N arratives and Experiences of Commercial M otorbike Riders in South-W estern U ganda. . .

done to the 'spoiled' girl. The worst type of damage presented was pregnancy while the girl is in school. They claimed that this is the worst offence because of its potential consequences. The girl would drop out of school if she were discovered, the man could be forced to either marry her or he could end up in jail or have to pay large fines. She could have complicated labour with the added possibility of death or bear a child with defects because she is still young, she would never make a good mother or wife because of her immaturity, she would always blame the man for taking her out of school and thus never be able to love or respect him well enough. Therefore, abortion is a necessary evil in the face of pregnancy of a schoolgirl. Seventeen participants mentioned instances that they were involved with a schoolgirl. "When it comes to a schoolgirl, the best thing is to have an abortion," they reasoned. Those who are not brave enough to suggest abortion often deny having anything to do with the pregnancy and would even go as far as moving out of the area.

Ken: How can a poor man go for a schoolgirl?

Interviewer: I sit only schoolgirls that carry out the abortion?

Ken: That is what I think. If one fears getting imprisoned, the solution is abortion. In case one does not have money, the person does not go in for schoolgirls. He only looks at them and lets them pass by.

Interviewer: D oes that mean that the poor do not go in for schoolgirls?

$\mathrm{K}$ en: No, they cannot, because the schoolgirls want money and once they get pregnant, the boy will have to look for money for the abortion. The cost depends on how grown the pregnancy is. If it is four months, the abortion will cost 40,000 U ganda shillings, and if it is six months it will cost 60,000 $U$ ganda shillings.

A frican Journal of Reproductive $\mathrm{H}$ ealth $\mathrm{V}$ ol. $9 \mathrm{~N} 0.1$ A pril 2005
Junju: If you come across a girl on the street who is not a student and you make her pregnant, that one we do not do the abortion. She remains with her pregnancy until birth. But if she is a student, definitely you have to do the abortion.

In addition to schoolgirls, when asked about which other groups of women often resort to abortion, participants in the focus group discussions mentioned commercial sex workers, whom they claimed could not afford to lose income from clients during the time they are pregnant. They also mentioned women who know they are infected with HIV, because they were not sure about the future of their unborn babies; and married women who conceived another man's child out of wedlock but do not want their husband to know due to the fear of the consequences. Such consequences include divorce, separation, punishment in the form of physical violence like battering, isolation, 'revenge promiscuity' where the husband seeks out new sexual partners to settle scores with his cheating wife, or social stigma and shame when outsiders discover.

Participants felt that abortion by schoolgirls is justified because it is done to salvagetheir future and avoid the legal implications for the male partner. They however condemned abortion by the older women who are out of school, associating this type with immorality and evil because it is usually done out of 'selfish motives' and could have been avoided.

$M$ atiya: For these ones, abortion is a very stupid act since they are not schooling. I do not see why they kill these babies.

$L$ ukas: Sometimes the girl could be a prostitute such that this fatherless pregnancy would be a great burden to her. $O \mathrm{n}$ top of that she will be loosing her market of sexual partners when she is pregnant. Selfishness makes her abort the baby becauseshewants moremoney. 
152 A frican Journal of R eproductive $H$ ealth

$N$ egotiation of $A$ bortion: The $R$ ole of $M$ en Initiation of abortion was discussed variously. Some participants claimed that it is the girl who usually initiates thenegotiation of abortion, others claimed that it is the boy, and a few others claimed that it is usually a joint venture. Some claimed it is an individual decision, others argued that abortion is bargained between the two individuals in the relationship, and many others stated that it is indeed a social decision that is initiated, advocated for and facilitated by the wider institutions of family, relatives, friends and other institutions particularly education, religion and the legal-justice systems. There was consensus that the men often facilitate the abortion by providing the money needed including transport. However, in cases of disagreement, where a girl would insist on having the abortion contrary to the boy's opinion, then the girl is usually left to fend for herself.

Interviewer: And if the girl decides to do the abortion, does she come to you for some money for the abortion? Seth: A $h$ ah no. She only struggles on her own.

$M$ isu: Sometimes this boy might be lacking enough support to be responsible for the pregnancy, while at the same time he is scared of the girl's parents' hot reaction towards him. Sometimes the girl might be a student. So here if the girl is afraid of her parents, and the boy is scared of the prison, they sit together and decide on the solution of abortion.

John: When a schoolgirl tells me she is pregnant, I ask her how tough her parents or paternal aunt is. And in case they are tough... I magine a girl with a father in D ar es Salaam and a mother in G ulu. $0 \mathrm{n}$ returning, the father might do something horrible to me for spoiling his daughter, so I then ask how much an abortion costs. It often costs
$30,000 /=$ shillings or $25,000 /=$ in addition to the transport fares. I give it to her and let her go for the abortion. If she went in the morning, she returns at about 4.00 p.m. fine after everything has been done.

Paul: It varies. If I know that I will get into trouble with the girl's parents or if the girl still wants to go to school, we have the abortion.

Interviewer: Who decides on it?

Paul: I do and if she agrees, we go for it. She might however refuse to have the abortion.

While some participants claimed that the girls do not have much choice in the matter, particularly when the man decides to opt for abortion and would never support any resultant baby, others asserted that many girls are strong enough to challenge the suggestion of the men. This specifically applies for girls who are afraid of complications resulting from the abortion, or who want to settle down with the man. 0 ther girls would challenge the suggestion and go through a spectrum of other possible options before settling for abortion.

Sam: When she came to me, I told her to have an abortion. However, the reason for saying this was not that I really wanted to have the abortion. I was only measuring her level of understanding. Interviewer: Were you testing her?

Sam: Exactly. When I told her, she asked, "What if I die in the process of having this abortion? Why don't I just carry it full term and deliver the child?" In fact we never went ahead with the abortion.

Interviewer: You said she is now your second wife?

Sam: Yes. I myself suggested that we have the abortion. I wanted to know 
what her reasoning capacity is like. She told me she feared dying while having an abortion, yet she could easily have her child and then continue with her life after that. So I agreed with her.

Interviewer: How did it happen?

$L$ ule: This girl conceived and yet there was no way she could remain pregnant and stay at her place of work. Secondly she had just finished her senior four ( 0 ' level) exams. Her results were to return and she was very hopeful of going back to school to complete her education. $0 \mathrm{n}$ top of that, there was no way she could go back to her home and tell her parents that she had conceived. Then as an individual, she told me that there was no way she could afford to carry out the abortion. Instead she asked me for some money to facilitate the abortion.

Interviewer: How much was it? L ule: She asked me for three hundred thousand shillings to help her start up a business. After thinking about it, I decided that this would not be of benefit to me. When I told her that I was not going to give her money, she decided that if I could facilitate her, she was willing to have the abortion. Interviewer: What was your reaction? L ule: I had no option but to give her money and she carried out the abortion. 0 min: I only got a child with one student. The other student was just a sexual partner. She did not get pregnant.

Interviewer: What do you have to say about abortion?

0 min: Sincel have ever loved a student and made her pregnant, this is what I have to say about abortion. Y ou know, I also suggested that she should have an abortion. H owever, she refused and consoled me that she would be alright if she could complete her course. Nothing would happen to me. Interviewer: Was it you who had brought up the suggestion to have the abortion? 0 min: Yes, I am the one who brought up the suggestion, but she refused to do it.

Interviewer: Did you drop her or are you still with her?

0 min: Ah ah no. I am not with her. I left the area because I feared what her parents would do to me. So I came to work here to avoid the results of my wrongs (laughs).

Interviewer: What wrongs?

0 min: The pregnancy I have just told you about. I feared that things might become hot for me. Her parents could want me to be imprisoned.

Jude: ... I gave her money for the abortion and asked her to leave. It is now two months since I last saw her. And I have not had sex again. Interviewer: H asn't she ever returned? Jude: $\mathrm{N}$ o, she has not. She lives at her parents' home and keeps on sending me messages to visit her but I cannot go there. I do not want to go there. Interviewer: Is she still pregnant? Jude: Yes she is. I am not sure... because I told her to have the abortion. I know I will be in big trouble if I show up at her home. I might get imprisoned and I will be at a loss.

Interviewer: H ave you ever gone back since the time you told her to have the abortion?

Jude: $\mathrm{N}$ o I have never. I do not go there anymore. I told her it was up to her whether she had the abortion or kept the baby. I gave her $10,000 /=$ to help her but she is reluctant over it. It is really up to her whether she keeps the baby or has the abortion. I t is really up to her. 
154 A frican Journal of $\mathrm{R}$ eproductive $\mathrm{H}$ ealth

Some men claimed that they deny total responsibility for the pregnancy and leave the decision-making entirely to the girl.

Interviewer: $\mathrm{H}$ ave you ever had such an experience?

Bbaale: Yes, I have.

Interviewer: What happened? H ow did you react?

Bbaale: I denied all responsibility of it because I had already discovered that she was not patient. She is the girl that I was telling you about. She had no patience at all in her heart. I had begun suspecting that she had other men apart from me. I told her that it would be best for me to first see that child before accepting responsibility.

Interviewer: So what happened after the child was born?

B baale I had never seen anyone like him in my family. In fact he never looked like any of the people at my home. $\mathrm{He}$ resembled none of us.

Interviewer: D id you deny responsibility for the child after seeing it, or when she was still pregnant?

Bbaale: I denied responsibility of that child when she was still pregnant. I was able to give her a little assistance because she was pregnant. But I told her that I was not responsible.

$\mathrm{N}$ ot all the bodabodamen supported the idea of abortion. There was a M uslim who claimed it was better to marry the pregnant girl, face whatever punishment the society places on the couple and deliver the child. 0 ther participants explained that they always use condoms in order to avoid dealing with decisions about unwanted pregnancies. Thus, abortion has never been an issue for them. A few others, based on their Pentecostal or Catholic belief, condemned abortion, claiming that it is murder and that $\mathrm{God}$ would look unfavourably on murderers at judgment. A small number took into consideration the woman's health and thus refrained from abortion as an option.
A li: I cannot agree to such a proposal for abortion.
Interviewer: What about her studies?
A li: She can deliver first and then continue with her studies later.
Interviewer: What if you are told to cater for her school fees after giving birth, you who impregnated her, can you stand it?
A li: I agree and try all my level best to push her ahead with her studies.
Tinka: I do not believe in abortions: Interviewer: Why not?
Tinka: You can tell a girl to have an abortion and she dies in the process. I first loved my wife when she was at her parents' home. She conceived before coming to my house. I t was very possible for me to ask her to have an abortion, but I decided to take her into my home and stay with her. I never thought about abortion because I knew there was a possibility that she would die.

\section{Discussion}

In U ganda, as in other sub-Saharan and developing countries, induced abortion is still constitutionally illegal unless it is crucial for the survival or wellbeing of the mother and/ or foetus. Several studies $^{18-26}$ reveal that it is nonetheless widely practiced within these socio-legal contexts. Conditions surrounding induced abortion have been variously described in literature as unsafe, dangerous, complicated, clandestine, socially unacceptable, criminal, unprofessional, incomplete, often developing into sepsis or other reproductive health complications, or even fatal. According to Luboga, abortion is the number 
one cause of maternal mortality in $U$ ganda ${ }^{27}$, contributing up to $30 \%$ of these deaths. ${ }^{1,2} \mathrm{~A}$ review of medical records in four major hospitals in the country estimated 5,000 admissions for incomplete abortions. ${ }^{28}$

This paper analyses the narratives of bodabodamen about their knowledge, attitudes and experiences with abortion; focussing on meanings, values and interpretations of the practice in their daily reality. It presents the tensions and contradictions within this male social group, revealing the polyvocality within and among individuals as well as the group. Albeit being indepth and detailed, the results presented here do not necessarily reflect the general picture, particularly because the sample was small and not representative of the population. Participants in the in-depth interviews and case studies were selected because they were available and willing to participate, and for the latter phase because they had experienced relevant social phenomena. Rather than reveal incidence levels of abortion, the paper provides a deeper appreciation of the heavily laden socio-cultural context in which it is negotiated, conceived, designed, operationalised, discussed and experienced.

The illegality of abortion in contexts where it is widely practised has a strong bearing on the research process and data obtained from studies about the practice. ${ }^{28,29}$ The need for study participants to disassociate themselves from the practice in certain spaces, public discourse, debates and indeed research activities implies that involvement in abortion will be under-reported, particularly in short-term, fast and sweeping research surveys. ${ }^{30,31} \mathrm{It}$ is therefore important to develop research methods that are sensitive to the various contexts in which abortion occurs. 32,33 Researchers must of necessity take on board the multilayered implications for participants, of revealing knowledge and participation (at whatever level) in the practice. 0 ur study reveals that research designs that provide for flexibility in structure, open-ended discussions and grounding research questions in the data collected empower participants to express themselves in their own style about even socially proscribed practices like abortion..$^{18} \mathrm{Q}$ ualitative methods, specifically individual interviews in combination with focus group discussions, are powerful tools for eliciting information about practices that are shrouded in secrecy, associated with shame or immorality and heavily laden with strong personal and cultural values. ${ }^{29,34}$

This study confirms others ${ }^{35-37}$ that emphasise the importance of establishing a relationship of trust and rapport between the researcher(s) and study participants. As the research progressed, bodabodamen zeroed down on a particular researcher whom they were able to confide in and open up to about specific individual sexual experiences. BK, who is motherly in disposition, was nicknamed 'Mama' by participants. Several bodabodamen often sought consultation with her to seek advice on pressing personal problems, including some that are over and beyond our research questions. 0 ther bodabodamen avoided her, preferring to confide in the two younger researchers.

Participants often stressed the importance of our confidentiality statement, mentioning expressions like "I am only telling you this because I know that you will not tell on me," "no one must know about this," "even my friends don't know about this event in my life, but I am telling you". Field notes and debriefing sessions came in handy, where participants asked us to stop the tape recorder so that they could speak to us off record. Therefore, research about secret, illegal and socially unacceptable phenomena not only necessitates access to the study communities, but also demands time, trust building, sensitivity and must be reciprocal. The role and positionality of the researcher(s) is significant in determining how much and what form of information study participants would grant them access to.

0 ur study reveals the ambivalence surrounding attitudes to and practice of abortion among 


\section{A frican Journal of R eproductive $H$ ealth}

the study participants. Even though they were aware that it is illegal, many men had actually been involved in abortion at varying levels. They had played significant roles as instigators, facilitators, collaborators, transporters, advisors, informers, supporters or even punishment givers. A nalysis of their narratives reveals that their lay interpretations of the practice range from 'dependable saviour' or 'a solution for many problems' to a 'deceptive sin'. Several paradoxes of the practice reflect tensions and conflict rife within the lay ethos of reproductive health in this socio-cultural context.

While abortion is discussed as murder because it is the termination of a foetus, and could possibly lead to the death of the aborting mother, it is also presented as a life-saver for the impregnating man, a solution that promises to give another lease of life to an immature pregnant unmarried female, and the birth of a new chance to continue with education. It is also seen as a necessity for a stable marriage for women who have conceived as a result of extramarital unions, continued residence and employment in a locale to an otherwise guilty man who may end up in prison or have to forcefully shift to a new area in order to avoid punishment or the unwanted responsibilities of fatherhood, and continued income to commercial sex workers. The apparent physical death represented in the act of abortion simultaneously signifies (re)birth to various social processes necessary for continued achievement within this context. Perhaps this contradictory potential explains the prevalence of the 'necessary evil'.

Conflict and tension within the function of abortion in the diverse private spheres of the actors including the pregnant female, her sexual partner, their couple as a unit, their immediate family and peers. Within the public sphere constituting social expectations, values, norms, accepted sexual conduct, laws - state, religious and cultural - notions of respectability, family honour, shame and stigma are deeply evident in the narratives. Privately, the girl's body is the site of the abortion. The experience is directly traumatic for her. She bears the individual responsibility for and public evidence of otherwise unknown and often illegitimate sexual activity. Society condemns her for the pregnancy, the abortion or the delivery of the child. I is the girl whose future reproductive life is most affected by abortion. E ven if it may salvage her education, marriage or career as a commercial sex worker, the abortion also negatively impacts on these areas, for example, lack of concentration in school leading to lower grades and less pleasure from sex. Therefore, the abortion experience has divergent consequences for the girl. It is both good and bad. She carefully negotiates between these two poles.

Similarly, the impregnating man is faced with the task of convincing the girl to undertake the abortion without necessarily revealing the danger involved, providing her with the necessary money to pay for the services, facilitating her transport to and from the venue of abortion, paying hospital fees in case of post-abortion care, and is still faced with the possibility of imprisonment even after the abortion - particularly if there are resultant complications, including death, that break the secrecy of the act. Thus, while it could solve the man's problems of imprisonment for impregnating a minor, paying heavy fines, changing residence, denying one's own flesh and blood or aforced marriage, abortion is also rife with possible difficulties for the man at the private level.

Furthermore, participants reported that most sexual relationships do not survive the event of an abortion particularly due to guilt, broken trust and inherent conflict. Therefore, abortion negatively affects the couple in the long run even though it may save them from stigmatisation and ridicule in the immediate future.

The contradictions are evident in the public social realm as well. Whether legal, religious or cultural, the instruments of law in $U$ ganda prohibit abortion. According to the Penal Code 
"A bortion? That's for women!" N arratives and Experiences of Commercial M otorbike R iders in South-W estern U ganda. . .

Act of $U$ ganda ${ }^{38}$, sections 136, 137, 138, 205 and 217, five forms of abortion are legally acknowledged with punishment for felony ranging from three-year to life imprisonment, with the exception of 'surgical operation' to save the mother's life or in cases of foetal deformity. Therefore, one can appeal to state law to defend and prosecute an act of abortion, depending on interpretation of intention. Furthermore, while abortion is condemned and frowned upon in unwritten customary cultural law of the society, the act of an unmarried girl having an illegitimate child brings worse shame to her person, her partner and her family. Similar findings have been reported elsewhere. ${ }^{18}$

U gandan education policy stipulates that her opportunity to a prosperous future earned through completing school is terminated when she carries the pregnancy to full term. Parents withdraw financial support, the girl is forced into an early marriage and left in the care of her partner to fend for herself and her child. This means that her chances of a decent livelihood or skilled employment are withdrawn. In such circumstances, the parents cannot be prosecuted by law for neglect of responsibility, even when the pregnant girl is still a minor who has a right to education. Instead, the man responsible for the pregnancy is faced with possibilities of imprisonment or payment of heavy fines. Therefore, the same law that condemns abortion also creates social pressures that necessitate abortion. The reputation of people known to be involved in abortion is tainted, specifically based on ideologies of religion, cultural taboos and legal frameworks that attach significant negative social interpretations to abortion as murder, evil, sin, a crime, 'depletion of the clan' or 'the death of a returning ancestor'.

Like most studies, ${ }^{20,22,41,42}$ the narratives of our male participants highlight the fact that it is predominantly adolescents (often students) who have abortions in this context. This confirms other reports from U ganda, which claim that $54 \%$ of women have their first birth before the age of 18 years, $43 \%$ of 15 -19-year-olds begin childbearing, and complications of pregnancy, childbirth and unsafe abortions are the major causes of abortion for women aged 15-19 years. ${ }^{1,2}$ U nfortunately, statistics about abortion are hard to come by. Similar to recent studies from M alawi, South A frica and Cameroon, ${ }^{22,20,41}$ all the experiences with abortion in our data involved a student. This does not mean that abortion is not occurring among older or married women ${ }^{39,40}$ Rather, it points to perhaps greater male involvement and awareness of abortion within a couple if the female sexual partner is below the age of consent, unmarried and/ or a student. Such women are more dependent on the man to suggest solutions because they are faced with graver social consequences than their adult married counterparts. Furthermore, the impregnating man in a sexual relationship with an unmarried minor who may or may not be attending school faces severe social consequences if the pregnancy is carried to term. Thus, male involvement in sexual relationships is not so much based on the fact that the men care or are concerned about the wellbeing of the girl, but rather they are concerned to save themselves from a diverse range of punishments.

A lay theory of 'spoiling a girl' (ok wonoona omuwala) was frequently employed to justify the need for abortion. By 'spoiling', participants referred to a range of activities that include suggesting sex, having sex, introducing one to a life of pleasure, impregnating and ruining one's chances of continuing with education. Participants discussed the assumption of purity, innocence and ignorance of sexual activity on the part of young women as though it were factual. Therefore, men who interact with 'pure girls' are often described as spoilers - out to defile the girl and rid her of her innocence. Therefore, they claimed that guilt and shame about sexual interaction with a 'pure girl' justifies having the abortion or the resultant socio-legal punishment heaped upon the man. Interestingly, there appears to be a continuum of 


\section{A frican Journal of R eproductive $H$ ealth}

degrees of 'spoiling' a girl, running from whether she is a school-going virgin minor with prospects of a bright future, a sexually experienced student, an out-of-school virgin minor, a minor, or a sexually active out-of-school minor. The more the degree of spoiling, the higher the chances of turning to abortion as a solution because then the socio-legal punishment would be greatest. Participants were clear about when their theory of 'spoiling a girl' does not apply. Such times include when the girl is already publicly known to be sexually active, for example, married girls, or young mothers, or promiscuous young women.

Themen's narratives revealed that an intersection of professional biomedical and lay reproductive health therapies facilitate and maintain the flourishing prevalence of abortion. Professionally trained health personnel at all levels, pharmaceutical dealers ranging from graduate pharmacists to mere drug store attendants, traditional birth attendants, faith healers, elderly relatives, knowledgeable peers and concerned family members all interact as providers of abortion services. This meshing of diverse abortion services provides a range of available options with various negotiable prices. The men reported sporadic utilisation of the services, often starting with the cheaper lay alternatives and later referring cases involving complications to professional therapies. 0 thers mentioned recommending combined usage of abortion therapies.

The secrecy involved in abortion leads to unsafe practices going unreported, uncorrected and unresearched. The secrecy of abortion pharmacology and procedure marks this terrain as sacred, secret, specialist knowledge that is available to an inner circle of a few practitioners. Compounded with the gaps in knowledge between health care providers and their clientele, available knowledge about what occurs in abortion settings is interwoven with myths, falsities, misconceptions, lies, fabrications and misunderstandings. This was evident in our data, and has severe implications for reproductive health policies and interventions targeting abortion. U nless an emic understanding of hidden practices is achieved, it is impossible to design appropriate programmes, policies and interventions. There is an urgent need for more research into the social and private world of abortion in contexts characterised with secrecy.

$\mathrm{H}$ eterosexual monogamy is a highly prized sexual practice advocated by sexual health education and anti-A IDS campaigns in U ganda. H owever, our group of highly mobile and virile working men emphasised that the expectations and demands of monogamy are at best an illusion in their circumstances. Their employment means that they have steady access to cash, which gives them higher bargaining power for extramarital sexual services; they are highly mobile; frequently crisscrossing rural-urban divides and migrating into peri-urban settings while simultaneously maintaining a wife at home., 8,10 Therefore, extramarital sexual activity with both casual and regular partners, often in either simultaneous or concurrent multiple partnerships, is high among these bodabodamen. However, their attitudes towards contraception were highly ambivalent, their use was mostly sporadic, and their knowledge was highly erroneous. ${ }^{42}$

The rampant sexual activity, in combination with low regard for contraception, perhaps explain the prevalent necessity of recourse to abortion as an inevitable and ultimate solution for unwanted sexual health problems. Just as contraception was relegated to the female domain ${ }^{42}$, preliminary data analysis revealed that participants were pushing issues surrounding abortion into the realm of women. "A bortion? That's for women!" is a dominant category ${ }^{16}$ of our initial analysis. H owever, subsequent repeated field interactions suggested that abortion is a major sexual and reproductive health issue that these male participants grapple with in their sexual and social relationships. It is important, therefore, to address the question: 'why the need to relegate abortion to women?'

A frican Journal of Reproductive $H$ ealth V ol. $9 \mathrm{~N} 0.1$ A pril 2005 
As observed earlier, the site for abortion is the woman's body. Therefore, the physical process in isolation is indeed a woman's issue. H owever, decisions about abortion are often instigated by the man, his family or his peers, particularly in consideration of the negative consequences to his private and social life if the pregnancy is not permitted. E ven where the pregnant woman consults her male sexual partner for advice, or when she is not in favour of the decision to have an abortion, many times she lacks the negotiating capacity to act otherwise specifically because the man could coerce her into deciding in his favour by threatening to deny all responsibility of the pregnancy and the child. Faced with the possibility of a future as a single parent, the woman succumbs. The socio-legal environment in this context pre-dictates that owning up to abortion as a man's activity means admitting participation in crime. Therefore, the apparent need for disassociation and the need to apportion blame is easily dealt with by such claims.

Furthermore, the history of sexual and reproductive health in this context mainly neglects the involvement of men. Therefore, the act of pushing abortion into a woman's corner is a continuity of this discourse picked up from the service providers and utilised by potential male clients. H owever, it is mere rhetoric - a mastery of camouflage - that men have learnt to employ to disguise ignorance, lack of confidence, or involvement in the practice. It is important to read into this line; read beyond the surface and decipher the cry for discussion and involvement hidden within. Triangulation of research methods made this possible for us. Intertextuality and openness to polyvocality while interpreting research data is important for such narratives to come out.

\section{Conclusion}

Men play significant roles in abortion processes, often influencing the decision if the sexual relationship involves an unmarried young woman
- specifically students. Though a private action, abortion is socially scripted and often collectively determined by wider social networks. A disjuncture exists between dominant public health discourse and the reality of local men who relate with women at diverse levels. Interventions targeting men about abortion should include safe sex education, provide safe abortion services and create stronger social support mechanisms. Policies and laws should incorporate local knowledge and practice in order to be relevant to local realities.

\section{Acknowledgements}

The authors are grateful to the bodabodamen who participated very enthusiastically in the study. We acknowledge D r R. Pool for guidance particularly during the study design, and Prof. J. Whitworth for permission to publish the results.

\section{References}

1. Ministry of $\mathrm{H}$ ealth, $\mathrm{D}$ epartment of Community $\mathrm{H}$ ealth, Reproductive H ealth D ivision. Sex ual and $\mathrm{R}$ eproductive $\mathrm{H}$ ealth $\mathrm{M}$ inimum Pack age for $\mathrm{U}$ ganda. $K$ ampala: E arnest Publishers, 2000.

2. Ministry of $\mathrm{H}$ ealth, Reproductive H ealth D ivision. Five-year strategic framework 2000-2004. G overnment of U ganda, K ampala, 2000.

3. Ratcliffe AA, H ill AG and Walraven G. Separate lives, different interests: male and female reproduction in the Gambia. Bull W orld $\mathrm{H}$ ealth 0 rgan 2000; 78(5): 570-579.

4. Greene ME and Biddlecom AE. From absent to problematic: men in demographic accounts of reproduction. N ew York, Population Council, Research Policy D ivision 1997; working paper no. 103.

5. Presser H. D emography, feminism and the social policy nexus. Pop D ev Rev 1997; 23(2): 295-331.

6. Bledsoe C, G uyer JI and Lerner S. F etility and the $M$ ale $L$ ife $C$ ycle in the $E$ ra of $F$ ertility $D$ edine. O xford: IUSSP/ O xford U niversity Press, 1999.

7. Ringheim $\mathrm{K}$. When the client is male: clientprovider interaction from a gender perspective. Inter Fam Plann Persp 2002; 28(3): 170- 175. 
160 A frican Journal of $\mathrm{R}$ eproductive $\mathrm{H}$ ealth

8. N yanzi S, N yanzi B and K alinaB. U rban husbands with rural wives: migration, employment and sexual health in a high HIV risk area in U ganda. U rban H ealth D ev Bull 2003; 6(1\& 2): 79-86.

9. N yanzi S, Pool R and K insman J. N egotiation of sexual relationships among school-going adolescents. A ID S C are2000; 13(1): 83-98.

10. N yanzi S, N yanzi B, K alina B and Pool R. M obility, sexual networks and exchange among bodabodamen in south western Uganda. Culture $H$ ealth Sex 2004; 6(3): 239-254.

11. U ganda Bureau of Statistics. U ganda Population and $\mathrm{H}$ ousing Census - Provisional Results, 2002; http:/ / www.ubos.org/ 2002census.html

12. D irectorate of $D$ istrict $H$ ealth Services. M asaka district profile. DISH - U ganda, 2002; http:/ / www.uagandadisch.org/ masaka.doc

13. Levin A, D mytraczenko T, M cE uen M, Ssengooba $F$, M irembe F, $O$ kui $O$, et al. Costs of maternal health care services in M asaka $D$ istrict, $U$ ganda. Special I nitiatives R eport 16. Bethseda, MD: Partnerships for $\mathrm{H}$ ealth Reform Project, A bt Associates Inc., 1999.

14. M organ $\mathrm{DL}$ (E d). Successful F ocus $G$ roup $D$ iscussions. N ewbury Park, CA and London: Sage, 1993.

15. Stewart DW and Shamdasani PN. F ocus $G$ roups: Theory and Practice. N ewbury Park, CA and London: Sage, 1990.

16. Strauss $A$ and Corbin J. Basics of $Q$ ualitative R esearch: $T$ echniques and Procedures for $D$ eveloping the $G$ rounded Theory. Thousand $O$ aks, CA and London: Sage, 1998.

17. Roseanne $C(E$ d.). A nthropology of P regnancy $L$ oss: Comparative Studies in M iscarriage, Stillbirth and $\mathrm{N}$ eonatal D eath. Berg Publishers, 1996.

18. Johnson-Hanks J. The lesser shame: abortion among educated women in southern Cameroon. SocSa M ed 2002; 55(8): 1337-49.

19. Ahman $E$ and Shah L. Unsafe abortion: worldwide estimates for 2000. R eprod $H$ ealth $M$ atters 2002; 10(19): 13- 17.

20. Hollander D. Although abortion is highly restricted in Cameroon, it is not uncommon among young urban women. Inter $F$ am Plann P ersp 2003; 29(1): 49-50.

21. Calves AE . A bortion risk and decision-making among young people in urban Cameroon. Stud Fam Plann 2002; 33(3): 249-260.
22. Varga CA. Pregnancy termination among South A frican adolescents. Stud F am Plann 2002; 33(4): 238-298.

23. Henshaw SK, Singh $S, O$ ye-A deniran BA, AdewoleIF, I wereN and CucaY P. Theincidence of induced abortion in $\mathrm{N}$ igeria. Inter Fam Plann Persp 1998; 24(2): 156- 164.

24. K ebede $S$, Jira $C$ and M ariam DW. A survey of illegal abortion in Jimma hospital, southwestern E thiopia. E thiop M ed J 2000; 38(1): 35- 42.

25. K oster-O yekan W. Why resort to illegal abortion in Z ambia? F indings of community-based study in Western Province. Soc Sci M ed 1998; 46(10): 1303-12.

26. Johnston HB and Hill K. Induced abortion in the developing world: indirect estimates. Inter Fam Plann Persp 1996; 22: 108-114.

27. Luboga S. Adolescent sexuality in U ganda. U ganda Y outh Conference: F reedom E xtreme, K ampala U ganda, 2004.

28. K inoti SL, G afkin L, Benson J and N icholson LA. Monograph on abortion issues in $E$ ast, Central and Southern Africa: with policy implications. A rusha, Tanzania: TheCommonwealth Regional $H$ ealth Community Secretariat for $E$ ast, Central and Southern A frica, 1994.

29. Marston $\mathrm{C}$ and Cleland J. Relationships between contraception and abortion: a review of the evidence. Inter Fam Plann Persp 2003; 29(1): 6- 13.

30. H untington $D, M$ ensch $B$ and Toubia N. A new approach to eliciting information about induced abortion. Stud Fam Plann 1993; 24(2): 120- 124.

31. K han ME and Manderson L. Focus groups in tropical diseases research. H ealth Policy Plann 1992; 7(1):56-66.

32. Mundigo AI. Research methodology: lessons learnt. In: Mundigo AI and Indriso C (Eds.). $A$ bortion in the $D$ eveloping W orld. London: WHO \& Zed Books, 1999, 465- 476.

33. Barreto T, Campbell O M R, D avies JL, Fauveau V, Filippi V, Graham W, et al. Investigating induced abortion in developing countries: methods and problems. Stud Fam Plann 1992; 23(3): 159-170.

34. Helitzer-Allen D, Makhambera $M$ and Wangel A M. $O$ btaining sensitive information: the need for morethan focus groups. R eprod $H$ ealth $M$ atters 1994; 3: 75-82.

A frican Journal of Reproductive $H$ ealth V ol. $9 \mathrm{~N} 0.1$ A pril 2005 
"A bortion? That's for women!" N arratives and Ex periences of Commercial M otorbike Riders in South-W estern U ganda. . . 161

35. Le Compte MD and Schensul JL. D esigning and C onducting $E$ thnographic R esearch. Walnut Creek: Altamira Press, 1999.

36. Bernard HR. R esearch M ethods in A nthropology: $Q$ ualitative and $Q$ uantitative $A$ pproaches. $N$ ewbury Park: Sage, 1994.

37. Trotter $\mathrm{R}$ and Schensul J. A pplied ethnographic research methods. In: Bernard HR (Ed.). $\mathrm{H}$ andbook of $\mathrm{E}$ thnographic $M$ ethods. CA: A lamira Press, 1998.

38. The Penal Code Act of U ganda. 1950; http:// annual review.law.harvard.edu/ population/ abortion/ U ganda.abo.htm
39. Rutgers $\mathrm{S}$. A bortion admissions in rural $M$ atebeleland north province. $C$ ent A fr J M ed 2001; 47(9-10): 214-220.

40. Airede LR and E kele BA. A dolescent maternal mortality in Sokoto, $\mathrm{N}$ igeria. J 0 bstet $\mathrm{G}$ ynaecol 2003; 23(2): 163-165.

41. Lema VM and Mpanga V. Post-abortion contraceptive acceptability in Blantyre, $M$ alawi. $E$ A fr M ed J 2000; 77(9): 488-493.

42. N yanzi S, N yanzi B and K alina B. Contemporary myths, sexuality misconceptions, information sources, and risk perceptions of B odabodamen in southwest U ganda. Sex R oles 2005; 52(1-2):111119. 